\title{
The need for enhancers in gene expression first appears during mouse development with formation of the zygotic nucleus
}

\author{
Encarnación Martínez-Salas, ${ }^{1}$ Elwood Linney, ${ }^{2}$ John Hassell, ${ }^{3}$ and Melvin L. DePamphilis \\ Department of Cell and Developmental Biology, Roche Institute of Molecular Biology, Roche Research Center, Nutley, New \\ Jersey 07110 USA
}

\begin{abstract}
Microinjection of the firefly luciferase gene coupled to a thymidine kinase (tk) promoter provided a quantitative assay to evaluate the requirements for gene expression in individual mouse oocytes and embryos. Polyoma virus (PyV) enhancers had no effect on the level of gene expression or competition for transcription factors as long as the DNA remained either in the oocyte germinal vesicle or the pronuclei of one-cell embryos. Expression of injected genes could be observed in pronuclei because the signal that normally triggers zygotic gene expression in two-cell embryos still occurred in one-cell embryos arrested in $S$ phase. However, when the tk promoter was injected into zygotic nuclei of two-cell embryos, enhancers increased the number of embryos that expressed luciferase as well as the level of luciferase activity per embryo. PyV enhancer mutation F101, selected for growth in mouse embryonal carcinoma F9 cells, stimulated expression in developing two-cell embryos about seven times better than the wild-type PyV enhancer and competed effectively for factors required for transcription. These results were consistent with the fact that enhancers are required to activate the PyV origin of DNA replication in developing two-cell embryos but not in one-cell embryos. The maximum levels of gene expression in oocytes, one-cell embryos, and developing two-cell embryos $(1: 67: 21)$ were inversely related to the extent of chromatin assembly, but the need for enhancers was independent of chromatin assembly. Therefore, it appears that the need for enhancers to activate promoters or origins of replication results from some negative regulatory factor that first appears as a component of zygotic nuclear structure.
\end{abstract}

[Key Words: Mouse; embryos; oocytes; polyoma virus enhancer; thymidine kinase promoter]

Received July 6, 1989; revised version accepted August 18, 1989.

Enhancers are cis-acting sequences that activate RNA polymerase II transcription of linked genes independently of their orientation and distance, and play a major role in determining cell specificity of gene transcription (Serfling et al. 1985a). Enhancers also function as components of several eukaryotic origins of DNA replication (DePamphilis 1988). Previous microinjection experiments (Martínez-Salas et al. 1988) revealed that the polyoma virus $(\mathrm{PyV})$ origin core sequence required an associated enhancer component to initiate replication in developing two-cell mouse embryos, as it did in all differentiated mouse cells, but not in one-cell embryos that spontaneously retained their pronuclei and failed to cleave to the two-cell stage. Therefore, enhancers did not appear to be needed in mouse development until a zygotic nucleus was formed at the two-cell stage where

\footnotetext{
1Present address: Centro de Biologia Molecular, Cantoblanco, Madrid 28049 Spain; ${ }^{2}$ Duke University Medical Center, Durham, North Carolina 27710 USA; ${ }^{3}$ McMaster University, Hamilton, Ontario, L8S 4K1 Canada.
}

zygotic genes are first expressed. Nevertheless, several concerns remained.

If the mechanism by which enhancers activate replication origins differs from the way in which they activate promoters, this conclusion may apply only to the role of enhancers in DNA replication. In PyV, the genetically defined origin of DNA replication (ori) consists of two components, a core (ori-core) and an enhancer (see Fig. 1). PyV ori-core contains all of the cis-acting information required to initiate DNA replication in the presence of PyV T-ag (Martínez-Salas et al. 1988) and determines where DNA replication begins (Hendrickson et al. 1987; DePamphilis et al. 1988b), whereas the enhancer is required to activate the ori-core component in all mouse cells from the developing two-cell embryo to the adult animal (Muller et al. 1983; Veldman et al. 1985; Rochford et al. 1987; Martínez-Salas et al. 1988). The ability of an enhancer to stimulate ori-core dependent DNA replication in a particular mouse cell type correlates closely with its ability to stimulate transcription (Veldman et al. 1985; Campbell and Villarreal 1986; 
Hassell et al. 1986; Mueller et al. 1988). Mutations that alter one function also alter the other (Linney and Donerly 1983; Tang et al. 1987; Martin et al. 1988; Satake et al. 1988), and cis-acting alterations of the PyV enhancer region can allow viral DNA replication in mouse cells that are normally permissive (Amati 1985). However, some characteristics of enhancers in the PyV origin of replication differ from those of enhancers coupled to promoters. Although it was reported initially that either enhancer orientation can activate PyV ori-core from a distance (deVilliers et al. 1984), subsequent studies concluded that the enhancer must lie in proximity to the AT-rich motif of ori-core in either PyV (Hassell et al. 1986 ) or the closely related simian virus 40 (Chandrasekharappa and Subramanian 1987; O'Connor and Subramani 1988). Furthermore, although enhancers stimulate both the PyV early gene promoter as well as the PyV origin core, enhancers do not always stimulate both of these targets in the same cell type (Campbell and Villarreal 1988). Similarly, PyV origin activity is relatively constant regardless of the number and effectiveness of the enhancer elements, whereas promoter activity can vary up to 100 -fold (Veldman et al. 1985; Martínez-Salas et al. 1988; see also Table 2). Therefore, it is possible that PyV origin activity assayed only some of the properties of enhancers.

Other concerns included the possibility that spontaneously arrested one-cell embryos do not exhibit the same regulatory controls on DNA replication and gene expression that are present during development. Since transcription from zygotic genes is first detected at the two-cell stage of mouse development /Clegg and Piko 1982), it appeared inappropriate for PyV and SV40 early gene promoters to express the PyV $\mathrm{T}$ antigen required for PyV DNA replication in one-cell embryos that remained morphologically as one-cell embryos. Furthermore, PyV DNA injected into one-cell embryos was injected only into the male pronucleus. Because male pronuclei are derived from sperm nuclei, they may exhibit unique properties because their chromatin composition changes from protamines to histones (Poccia et al. 1984). In contrast, the smaller female pronucleus, which is derived from the oocyte germinal vesicle, is not subjected to this change. Finally, DNA replication could not be used to assay for enhancer activity in oocyte germinal vesicles because oocytes do not replicate their own DNA or foreign DNA.

To resolve these concerns, the herpes simplex virus (HSV) thymidine kinase (tk) promoter (McKnight et al. 1981) was coupled to the firefly luciferase gene (deWet et al. 1987), a sensitive reporter gene that allowed promoter activity to be measured in individual cells, and injected into the nuclei of mouse oocytes and preimplantation embryos. This promoter responds to stimulation by a variety of enhancers in differentiated cell lines, including those PyV (Fig. 1; Edlund et al. 1985; Mueller et al. 1988). The results confirmed our original hypothesis and demonstrated that injected genes respond to the same controls that regulate endogenous gene expression during preimplantation development, but that the level of expression and the need for enhancers depends on the type of nucleus in which the DNA exists. In addition, the data demonstrated that at least one enhancer mutation selected for its activity in undifferentiated mouse embryonal carcinoma cells is even more active in preimplantation mouse embryos.

\section{Results}

Gene expression in individual mouse oocytes and embryos is promoter dependent

A firefly luciferase expression vector was injected into the germinal vesicle of oocytes, either pronucleus of one-cell embryos, and one of the two zygotic nuclei in two-cell embryos. Meiotic maturation of oocytes into eggs was prevented by culturing them in dbcAMP. Onecell embryos containing two haploid pronuclei were prevented from becoming two-cell embryos containing two diploid zygotic nuclei by culturing them in aphidicolin, a specific inhibitor of DNA polymerases- $\alpha$ and $-\delta$. As discussed later, spontaneously arrested one-cell embryos (Martínez-Salas et al. 1988) and aphidicolin-arrested one-cell embryos were indistinguishable in their response to injected genes. Two-cell embryos were allowed to continue development to the morula-blastocyst stage.

The level of luciferase expression was dependent on the amount of DNA injected (Fig. 2), which was stable in these nuclei for 3 days (Wirak et al. 1985; Martínez-Salas et al. 1988). Optimal expression of luciferase in one-cell and developing two-cell embryos occurred with $0.6 \mathrm{pg}$ of DNA per nucleus, but oocytes required 1 pg of DNA per nucleus. Higher than optimum levels of DNA resulted in lower levels of gene expression, presumably because of DNA toxicity; two-cell embryos injected with $\geqslant 1$ pg of DNA per embryo did not continue development.

The level of gene expression was also dependent on the presence of the tk promoter and the type of cell injected. When the optimum amount of DNA was injected, the tk promoter (ptkluc) stimulated luciferase expression in one-cell embryos by 566-fold relative to the same plasmid without the promoter (pluc; Table 1). However, luciferase activity produced by ptkluc in onecell embryos was 67-times more than the activity produced by ptkluc in oocytes, and 21-times more than that in two-cell embryos.

In addition, the number of oocytes and embryos that expressed luciferase depended on the type of cell injected (Fig. 3). Elimination of the nonresponding cells, defined by the maximum activity of cells injected with pluc (Fig. 3), did not modify the relationship between the amount of DNA injected and luciferase activity in onecell and developing two-cell embryos (Fig. 2). Approximately $90 \%$ of the oocytes or one-cell embryos expressed luciferase ('responders'), but only $50 \%$ of the two-cell embryos responded to the injected gene (Table 1). Therefore, the average level of luciferase activity in two-cell embryos was about twice as great for responders alone compared to the total population (Fig. 2). 


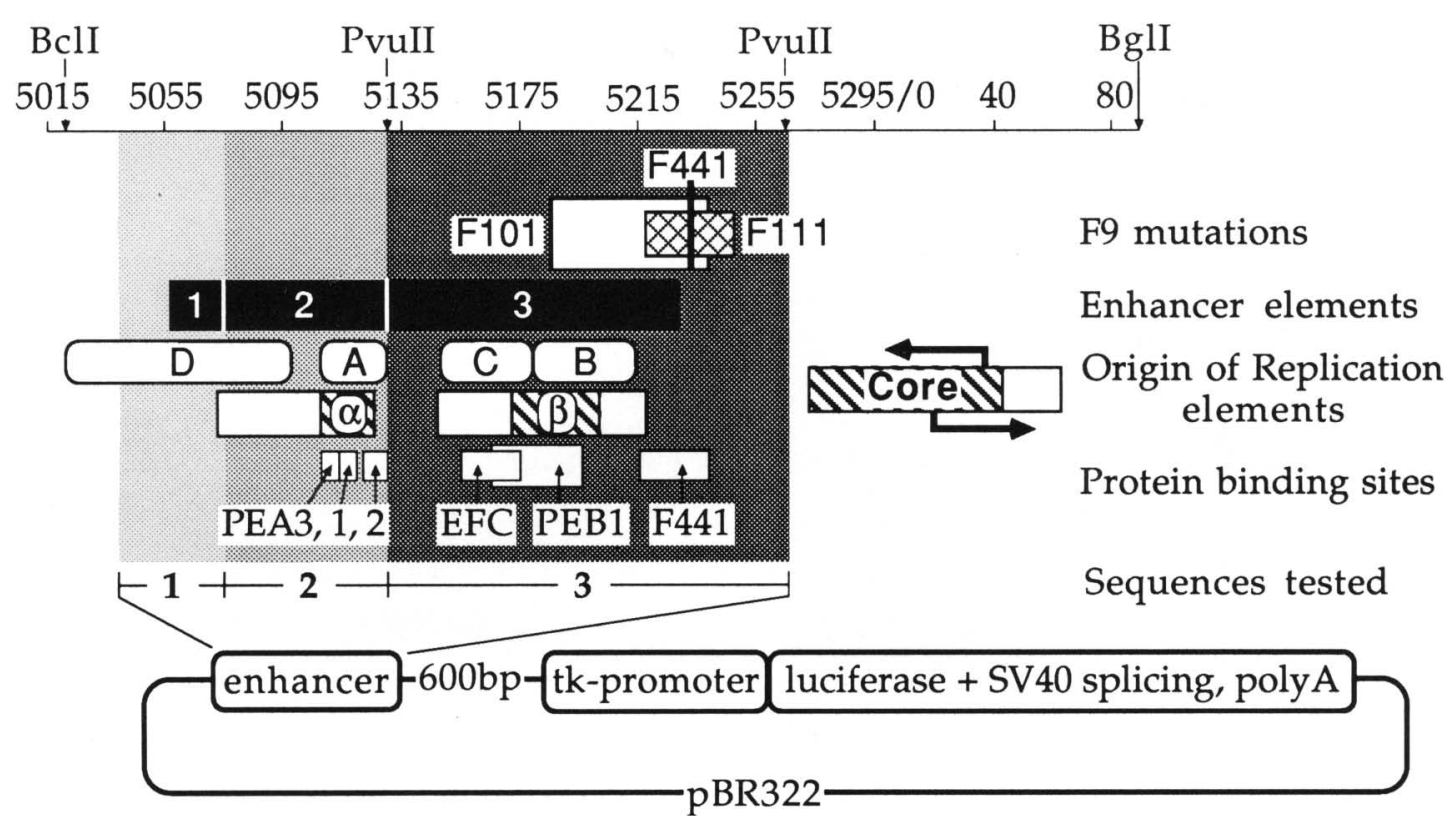

Figure 1. Polyomavirus (PyV) enhancer elements and luciferase expression vectors. Various combinations of PyV enhancer regions 1 , 2 , and 3 (shaded boxes) were cloned upstream of the HSV tk promoter coupled with the firefly luciferase gene and SV40 splicing and polyadenylation signals as described in Methods. The complete PyV enhancer is contained within a 241-bp DNA fragment defined by $B c I I$ and PvuII restriction sites that can be subdivided into regions 1 (nucleotides 5039-5072), 2 (nucleotides 5073-5130), and 3 (nucleotides 5131-5264). The essential sequences for PyV A2 enhancer regions 1, 2, and 3 are shown (solid bars) (Mueller et al. 1988). These regions interact to produce full enhancer activity (Mueller et al. 1988). Enhancer regions $1+2$ and 3 correspond closely with the borders of two functionally redundant elements, $\alpha$ (or $A+D$ ) and $\beta$ (or $B+C$ ), that are part of the origin of PyV DNA replication (Muller et al. 1983; Veldman et al. 1985). The origin also includes the core sequence, which encompasses the origin of bidirectional replication (arrows; Hendrickson et al. 1987; DePamphilis et al. 1988b). The essential origin sequences are shown (striped bars). DNAinding sites for putative enhancer-specific proteins (open boxes) include PEAl, 2, and 3 (Martin et al. 1988); EFC (Fujimura 1986; Ostapuck et al. 1986); PEB1 (Bohnlein and Gruss 1986; Piette and Yaniv 1986); and F441 (Kovesdi et al. 1987). The enhancer region of three PyV host-range mutants selected for growth in undifferentiated mouse embryonal carcinoma F9 cells (Fujimura et al. 1981) contains a point mutation at nucleotide 5233 (solid bar, F441), a 31-bp tandem duplication of the mutated region (crosshatched box, F111), or a 54-bp tandem duplication of this region (open box, F101). The nucleotide numbering system is explained in DePamphilis and Bradley (1986).

Gene expression in individual developing two-cell embryos is enhancer dependent, but not in oocytes and one-cell embryos

The ability of PyV enhancers to stimulate the tk promoter was assessed by introducing different combinations of the PyV enhancer regions $600 \mathrm{bp}$ upstream of the tk promoter (Fig. 1). Suboptimal amounts of DNA were injected to insure that promoter activity was not limiting under conditions where stimulation by enhancers was assayed (Fig. 2). Previous studies revealed that PyV enhancers were not required to activate the PyV origin of DNA replication in the male pronucleus of one-cell embryos although they were required in the zygotic nucleus of two-cell embryos (Martínez-Salas et al. 1988). Consistent with this result, the complete PyV enhancer (p123tkluc) had no effect on tk promoter activity in the male pronucleus of one-cell embryos, the oocyte germinal vesicle, or the female pronucleus of one-cell embryos (Fig. 4). The female pronucleus produced only half as much luciferase activity as its male counterpart. Furthermore, neither individual enhancer regions 1,2 , or
3 nor combinations of any two regions had a significant effect on tk-promoter activity in the male pronucleus (data not shown).

Surprisingly, the complete PyV enhancer stimulated gene expression in developing two-cell embryos by only threefold (Fig. 4). Combinations of two enhancer regions did not increase the activity over the promoter alone, and individual regions 1,2 , or 3 actually reduced tk promoter activity by threefold. The activity observed in the wild-type enhancer was due primarily to region 3 . Two tandem copies of regions 1 and 2 (p12 $\times 2$ tkluc) did not increase gene expression, whereas three tandem copies of region 3 (p3 3 tkluc) increased luciferase activity fourfold. This was in agreement with the relative efficiency of these sequences $(\alpha$ and $\beta$ ) in stimulating PyV origin activity in two-cell embryos (Martínez-Salas et al. 1988).

We considered the possibility that PyV enhancer mutations selected for their ability to stimulate gene expression in mouse embryonal carcinoma cells may be preferentially active in mouse embryos. PyV F101 contains an enhancer mutation that allows PyV to replicate 

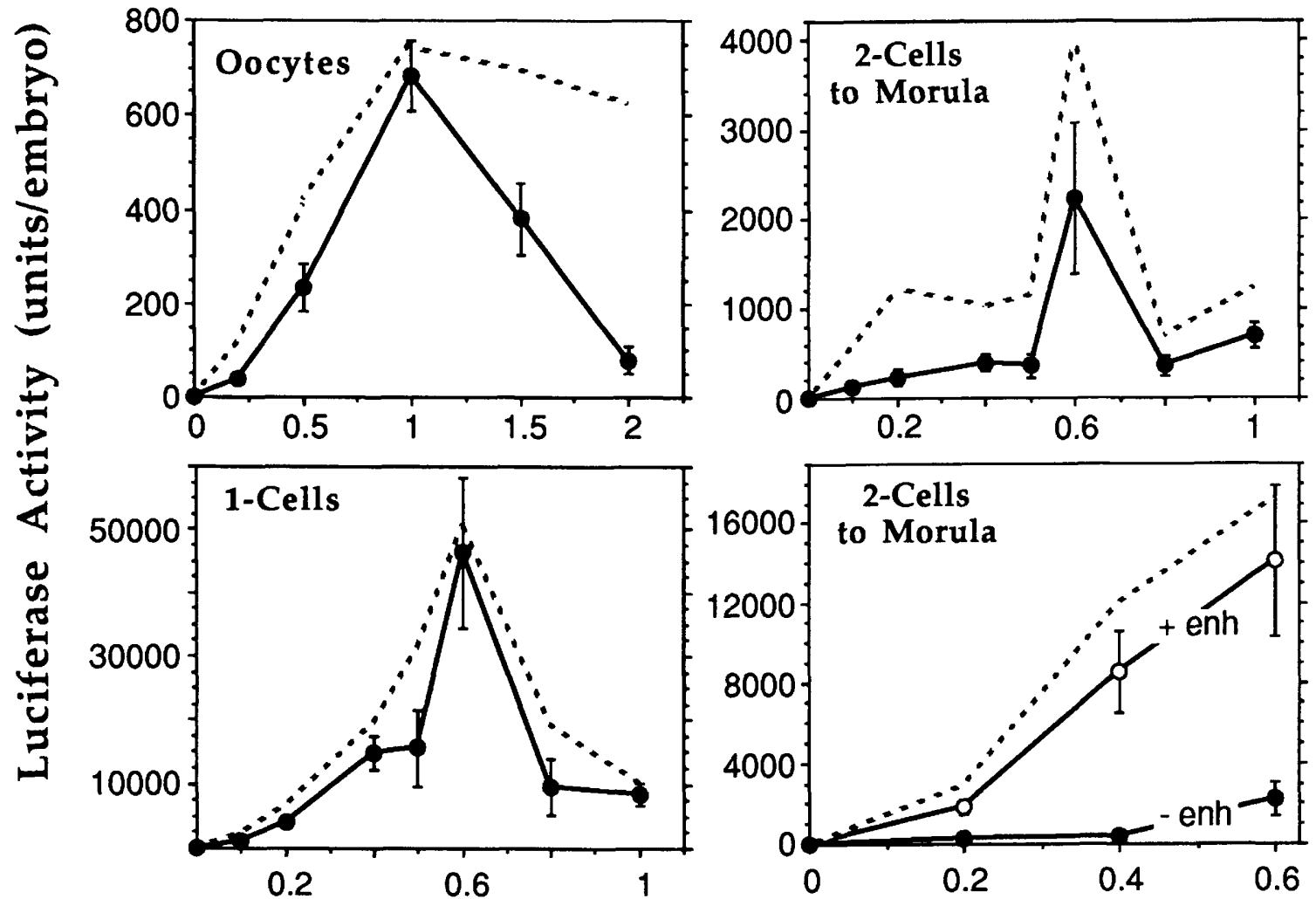

DNA Injected (pg/nucleus)

Figure 2. Dose response between amount of DNA injected and amount of luciferase activity produced. The luciferase expression vector ptkluc ( $\bullet$ ) was injected into the nucleus of mouse oocytes, one-cell embryos, and two-cell embryos. Survivors were cultured for $42 \mathrm{hr}$ before extracts were prepared from individual oocytes and embryos. Only injected two-cell embryos were allowed to continue morphological developmental in vitro. Luciferase activity was determined in each cell extract and the mean of the total population represented by the solid line. Error bars indicate the SEM. The discontinuous line represents the mean luciferase activity only of those embryos that responded to the tk promoter as illustrated in Fig. 3. The effect of the F10l enhancer was determined by injecting pFloltkluc ( + enh, O); the discontinuous line in this panel is also ' + enh.' Results with pF101tkluc injected oocytes and one-cell embryos were indistinguishable from those injected with ptkluc and therefore were not plotted.

in undifferentiated F9 cells much better than the wildtype enhancer (Fujimura and Linney 1982). When the F101 enhancer was tested in the zygotic nucleus of developing two-cell embryos, it stimulated the tk promoter 21 -fold. Stimulation was observed over a fourfold range of DNA concentrations, although the level of stimulation was not constant (Fig. 2). In contrast, the F101 enhancer had no effect on tk-promoter activity in oocyte germinal vesicles or either the male or female pronuclei of one-cell embryos (Fig. 4), regardless of the DNA concentration tested.

Enhancers increased the number of developing two-

Table 1. tk promoter activity in individual mouse oocytes and preimplantation embryos under conditions optimal for gene expression in each group

\begin{tabular}{|c|c|c|c|c|c|c|}
\hline \multirow[b]{2}{*}{ Cells assayed } & \multicolumn{2}{|c|}{ Mean \pm SEM } & \multirow{2}{*}{$\begin{array}{l}\text { Stimulation by } \\
\text { tk-promoter }\end{array}$} & \multirow{2}{*}{$\begin{array}{l}\text { Cells responding } \\
\text { to tk-promoter }(\%)\end{array}$} & \multicolumn{2}{|c|}{ Cells analyzed } \\
\hline & $-\mathrm{tk}$ & $+\mathrm{tk}$ & & & $-\mathrm{tk}$ & $\overline{+\mathrm{tk}}$ \\
\hline Oocytes & $57 \pm 7$ & $690 \pm 141$ & $12 X$ & 89 & 48 & 27 \\
\hline One-cell embryos & $82 \pm 20$ & $46,449 \pm 11939$ & $566 \mathrm{X}$ & 91 & 24 & 47 \\
\hline $\begin{array}{l}\text { to morula } \\
\text { (+F101 enhancer) }\end{array}$ & $24 \pm 3$ & $\begin{aligned} 2,210 & \pm 841 \\
14,094 & \pm 3780\end{aligned}$ & $\begin{array}{r}92 X \\
587 X\end{array}$ & $\begin{array}{l}52 \\
82\end{array}$ & 37 & $\begin{array}{l}83 \\
38\end{array}$ \\
\hline
\end{tabular}

Oocytes, one-cell embryos, (male pronucleus) and two-cell embryos were injected with either pluc (-tk), ptkluc (+tk), or pF101tkluc (+F101 enhancer). The amount of DNA injected and the time that each set of cells was cultured in vitro before harvesting were those determined to be optimal for luciferase expression in each case (Figs. 2 and 8). Luciferase activity was expressed as scintillations per 10 $\sec (1799$ scintillations $=1 \mathrm{pg}$ of purified luciferase). Uninjected embryos gave zero activity. Mean \pm SEM was calculated for the total cell population in each group. 


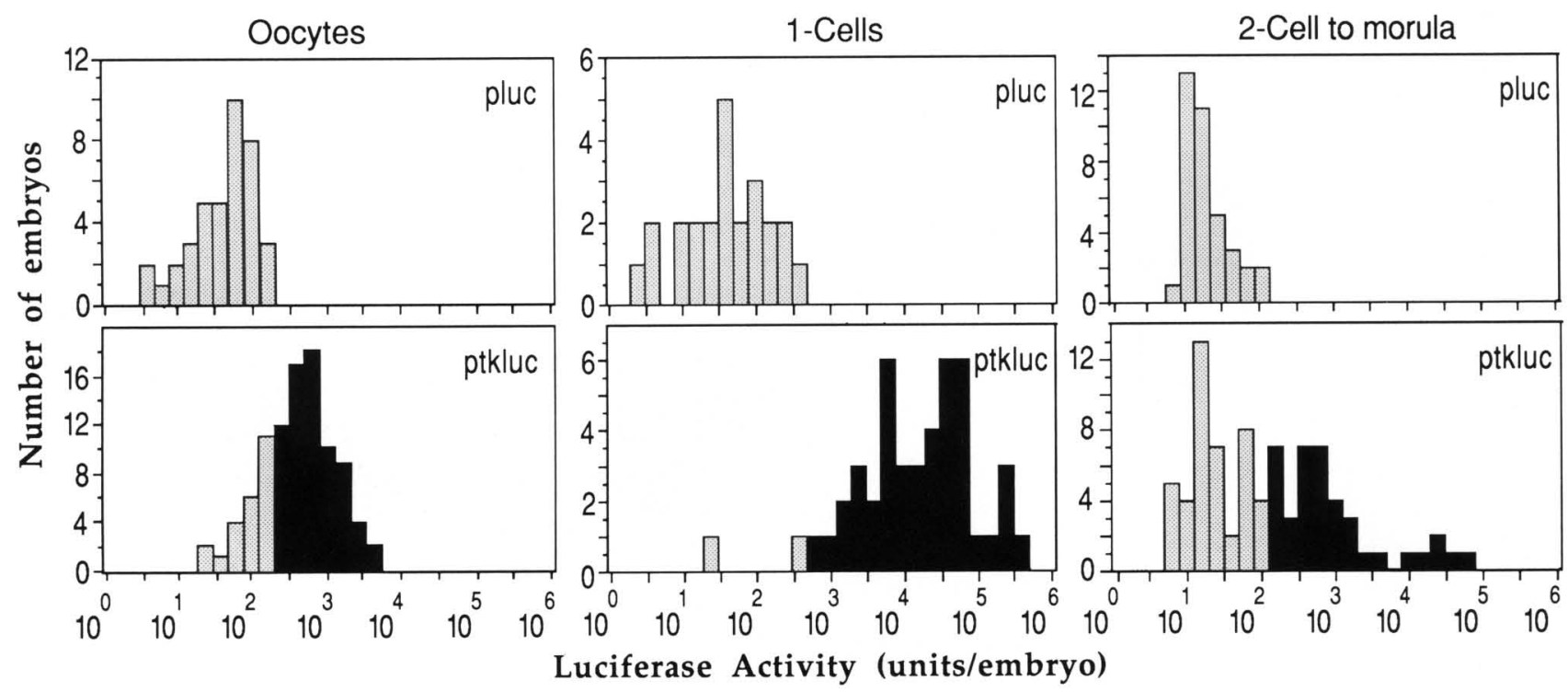

Figure 3. Promoter dependence of luciferase expression in individual oocytes and embryos. Luciferase expression vectors, either with (ptkluc) or without (pluc) the tk promoter were injected into the nucleus of mouse oocytes (1 pg of DNA), one-cell embryos (0.6 pg of DNA), and two-cell embryos (0.6 pg of DNA). Individual oocytes were harvested at $24 \mathrm{hr}$ postinjection, and individual embryos at 42 hr postinjection, and luciferase activity was measured. (Shaded bars) Cells expressing luciferase in the absence of a promoter; (solid bars) cells expressing luciferase in response to the tk promoter (i.e., responders).

cell embryos that responded to the injected gene as well as their activity. Under the conditions used to compare effects of enhancers (Fig. 4), 40\% of the embryos recognized the tk promoter alone, whereas $74-78 \%$ recognized this promoter when coupled to either three tandem copies of PyV enhancer region 3 or the F101 enhancer (Fig. 5). Thus, 2 of 3 of the embryos that did not use the tk promoter in the absence of an enhancer were fully active when an enhancer was present. This effect on the number of cells responding to the injected gene was not observed in one-cell embryos or oocytes /data not shown), consistent with the lack of enhancer stimulation of gene activity in these cells.

\section{The F101 enhancer is exceptionally active in two- to eight-cell embryos}

To identify the sequences responsible for the strong stimulatory activity of F101 in mouse embryos, the ability of various enhancer regions to stimulate the tk promoter was compared in developing two-cell embryos, undifferentiated F9 cells, and differentiated 3T3 cells (Fig. 6). The single point mutation in enhancer region 3 at position 5233 (F44l, Fig. 1) stimulated tk-promoter activity about fourfold in F9 cells and twofold in developing two-cell embryos relative to the activity observed with region 3 alone. A 31-bp duplication of the region
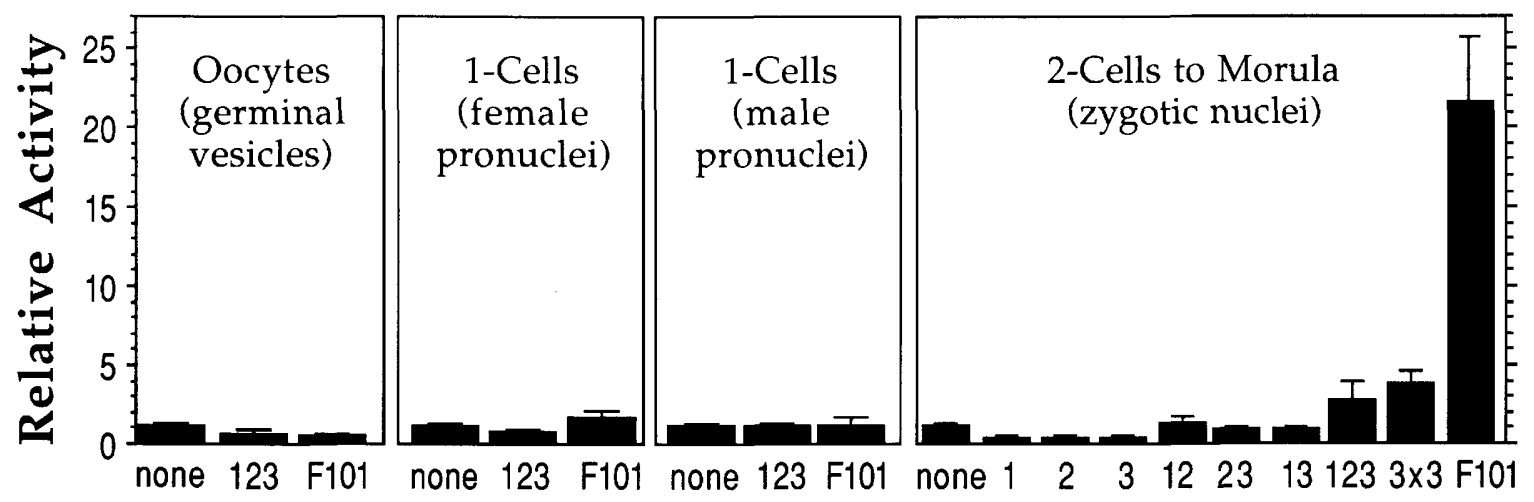

\section{Enhancers}

Figure 4. Relative effect of enhancers on the tk promoter in different types of nuclei. Luciferase expression vectors (0.4 pg of DNA) containing the tk promoter plus the indicated enhancer region (see Fig. 1) were injected into the germinal vesicle of oocytes, the male or female pronucleus of one-cell embryos, or one of the two zygotic nuclei in two-cell embryos. Luciferase activity was determined at $42 \mathrm{hr}$ postinjection, calculated as in Fig. 2, and plotted relative to ptkluc (none) for each type of nucleus. Error bars give the SEM for the 30-90 individual oocytes (the average is 55) or embryos used in each assay. Numbers refer to the various combinations of enhancer regions (Fig. 1). Three tandem copies of region 3 cloned into the ptkluc expression vector $(3 \times 3)$. 


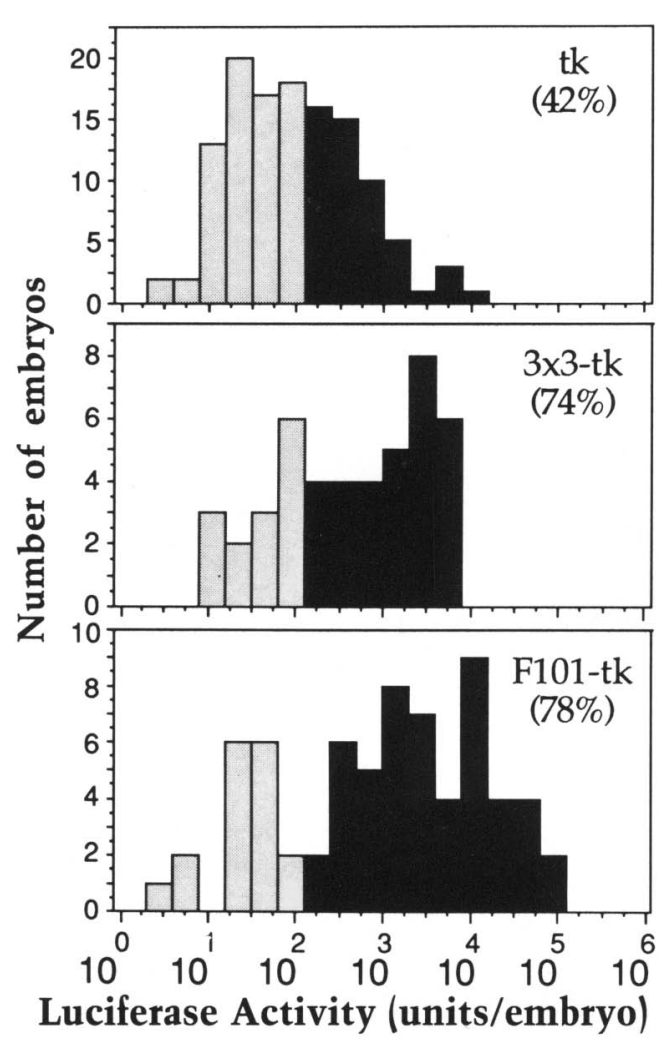

Figure 5. The effect to an enhancer on the number of embryos responding to the tk promoter and the level of promoter activity per embryo. Plasmid ptkluc (tk), p3 3 tkluc $(3 \times 3-\mathrm{tk})$, or pF101tkluc (F101-tk) was injected into one of the nuclei of twocell embryos (0.4 pg of DNA per nucleus) and luciferase activity of individual embryos measured as described in Fig. 3. Numbers in parentheses refer to the fractions of embryos responding to the tk promoter (solid bars) as illustrated in Fig. 3.

containing this point mutation (F111, Fig. 1) stimulated promoter activity in embryos about 7-fold but a 54-bp duplication containing this mutation (F101, Fig. 1) stimulated activity about 57-fold. The F101 enhancer region was highly preferred in mouse embryos because it stimulated the tk promoter only fourfold in 3T3 cells and sevenfold in F9 cells. This embryo-preferred enhancer activity resulted from a synergistic effect between the point mutation and the duplication; three tandem copies of wild-type PyV region $3(3 \times 3)$ stimulated the tk promoter only 10-fold (Fig. 6).

The F101 enhancer was five times more active in embryos that developed to the two- to eight-cell stage by 42 hr than in those that developed to morula (Fig. 6). Thus, F101 was at least 10 times more active in stimulating transcription in early cleavage embryos than in either 3T3 fibroblasts or undifferentiated F9 cells, and the activity in two- to eight-cell embryos was equivalent to that of ptkluc or pF101tkluc in pronuclei of arrested onecell embryos (c.f. Fig. 6 and one-cell embryos in Fig. 2). Because $\sim 60 \%$ of injected two-cell embryos developed to morula in the following $42 \mathrm{hr}$, luciferase activity per embryo for the total population of developing twocell embryos was less than for injected one-cell embryos (Table 1).
Developing two-cell embryos contain limited amounts of enhancer-specific binding factors

Developing two-cell embryos contain factors required for PyV replication that bind specifically to the PyV enhancer region but one-cell embryos do not (MartínezSalas et al. 1988). To determine whether enhancer-specific-binding factors were also required to activate the tk promoter under the same conditions, a $2: 1$ molar ratio of either P3 $\times 3$ tkluc or pF101tkluc and pF101 $\Delta \mathrm{T}$ was coinjected into one-cell and two-cell embryos. Luciferase expression was reduced $90 \%$ in two-cell embryos in both cases, whereas luciferase expression in one-cell embryos remained within the normal experimental variation (Fig. 7). These results suggest that developing twocell embryos contain limiting amounts of enhancerbinding factors. Since pF101 $\mathrm{T}$ competed for both $3 \times 3$ and F101 enhancers, one or more of these factors activates both wild-type and mutant enhancers.

\section{Expression of gene injected into one-cell embryos is coincident with the onset of zygotic gene expression}

Transcription from zygotic genes has not been observed prior to the early two-cell stage in development (Fig. 8A; Clegg and Piko 1982). Yet, genes injected into either pronucleus of one-cell embryos were expressed at high levels, even though the embryos remained morphologically at the one-cell stage. To resolve this paradox, we measured the time course for expression of ptkluc injected into one-cell embryos $4 \mathrm{hr}$ after they were isolated in aphidicolin [Fig. 8A inject (A)]. A lag of 16-20 hr was observed before any expression of luciferase activity was detected [Fig. 8B, 1-Cells (A)], suggesting that expression of the injected gene was delayed until the signal for zygotic gene expression was given (Fig. 8A). To test this hypothesis, one-cell embryos were held in aphidicolin for $16 \mathrm{hr}$ before injecting ptkluc [Fig. 8A, inject (B)], in which case luciferase expression began immediately [Fig. 8B, 1-Cells (B)], consistent with the time course resulting from injection of ptkluc into two-cell embryos that developed normally in the absence of aphidicolin (Fig. 8B, 2-Cells). Enhancers did not modify the time course for expression of the injected gene. Therefore, expression of injected genes that remain in the pronuclei of one-cell embryos is regulated by the same controls that determine when zygotic gene expression begins, and these controls are independent of DNA replication.

Injection of DNA into one-cell embryos, in the absence of aphidicolin, resulted in about $30 \%$ of them remaining in morphology as one-cell embryos (Wirak et al. 1985; Martínez-Salas et al. 1988). Luciferase expression from either ptkluc or pF101tkluc in spontaneously arrested one-cell embryos was equivalent to that in onecell embryos whose DNA replication was inhibited by aphidicolin (Fig. 9), suggesting that untreated one-cell embryos were arrested before they ended their S phase. Incubation of injected two-cell embryos in aphidicolin resulted in $70 \%$ repression of luciferase activity. Most of these embryos $(>65 \%)$ stopped dividing after cleavage to the four-cell stage and the remainder stayed at the two- 


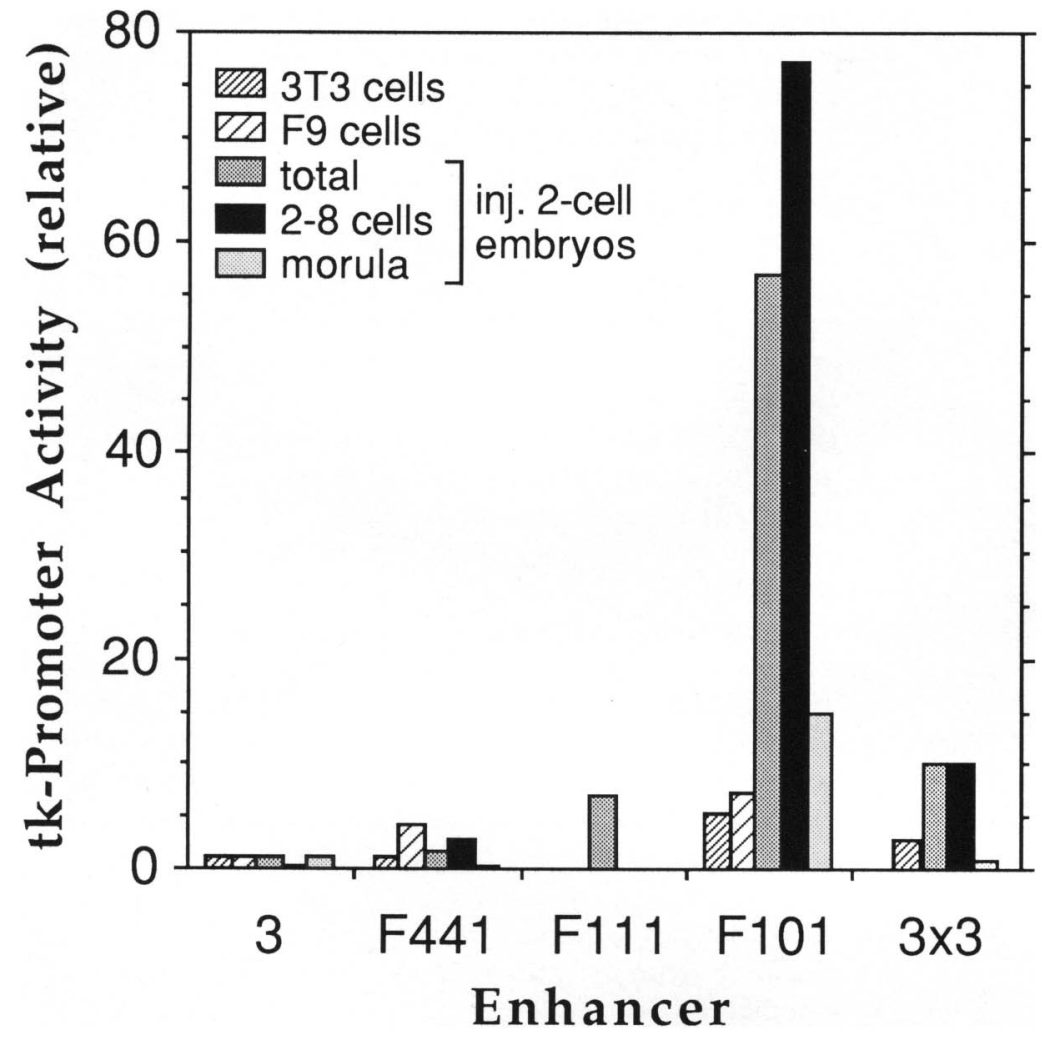

Figure 6. Effect of F9 PyV enhancer mutations on regulation of gene expression in mouse 3T3 fibroblasts, undifferentiated F9 embryonal carcinoma cells, and developing two-cell embryos. 3T3 cells were transfected with p3tkluc (3), pF44ltkluc (F441), pF101tkluc (F101), or p3 $\times 3$ tkluc $(3 \times 3)$ as described in Methods. Data from transfection of F9 cells were taken from Linney and Donerly (1983). One of the nuclei of two-cell embryos was injected with $0.4 \mathrm{pg}$ of the indicated plasmid, and luciferase activity measured 42 dividual embryos. tk-Promoter activity was expressed relative to that obtained with p3tkluc. tk-Promoter activity in the two- to eight-cell embryos and morulas that developed from injected two-cell embryos was expressed relative to 3 tkluc in the total population of developing two-cell embryos. cell stage, consistent with the fact that most two-cell embryos completed DNA replication before plasmid DNA was injected (Fig. 8A). Therefore, the properties of gene expression observed in one-cell embryos incubated in aphidicolin are unique to pronuclei and not a consequence of arresting any nucleus in $\mathrm{S}$ phase.

To consider the effects of arrest at other phases in the cell cycle, one-cell embryos were injected with ptkluc and then treated either with cytochalasin B to disrupt actin filaments and prevent pronuclei disorganization, or with nocodazol to prevent completion of mitosis by disruption of microtubules. Gene expression was repressed in the presence of these drugs (Fig. 91. Since the same results were obtained with F101 (Fig. 9) and pl231tkuc (data not shown), enhancers did not modify the response to these experimental conditions. Expression of genes injected into one-cell embryos that continued development to the two-cell through morula stages was only $10 \%$ of the activity observed in arrested one-cell embryos, regardless of the presence or absence of the F101 enhancer. These results are in agreement with similar experiments using the PyV origin of replication (Wirak et al. 1985; Martínez-Salas et al. 1988), the tk promoter (Chen et al. 1986), and the metallothionein promoter (Stuart et al. 1984). Taken together, these results reveal that some aspect of nuclear structure determines which cis-acting sequence elements will be required to express genes or to initiate DNA replication in a particular cell.
Assembly of injected DNA chromatin is inversely correlated with the level of gene expression, but it is not correlated with the need for enhancers

The rate and extent that injected DNA is assembled into nucleosomes can be assessed using gel electrophoresis to monitor conversion of circular, topologically relaxed DNA into circular, superhelical DNA /Gargiulo et al. 1984). pF101, a plasmid containing the PyV ori-core coupled to the complete F101 enhancer region and the PyV large $\mathrm{T}$ antigen gene, was injected into one- and two-cell embryos. As observed previously in mouse oocytes (Chalifour et al. 1986), injected DNA that consisted of $80 \%$ superhelical DNA (form I) was converted into topologically relaxed molecules within the first 20 min after injection. Only $10-15 \%$ of the injected DNA remained as form I (Fig. 10). By $8 \mathrm{hr}$ postinjection, $70 \%$ of the DNA injected into oocytes existed as form I, whereas $35 \%$ of the DNA injected into two-cell embryos and $15 \%$ of that in one-cell embryos was superhelical (Fig. 10). Expression of injected genes reached its maximum level in oocytes at this time (data not shown; Chalifour et al. 1986), but not in one-cell and developing two-cell embryos (Fig. 8). By $45 \mathrm{hr}$ postinjection, when luciferase expression was maximum in both one-cell and developing two-cell embryos, $70 \%$ of the DNA injected into two-cell embryos but only $10 \%$ of the DNA in one-cell embryos was superhelical. Comparison of these data with those in Figures 2 and 4 revealed that assembly of 


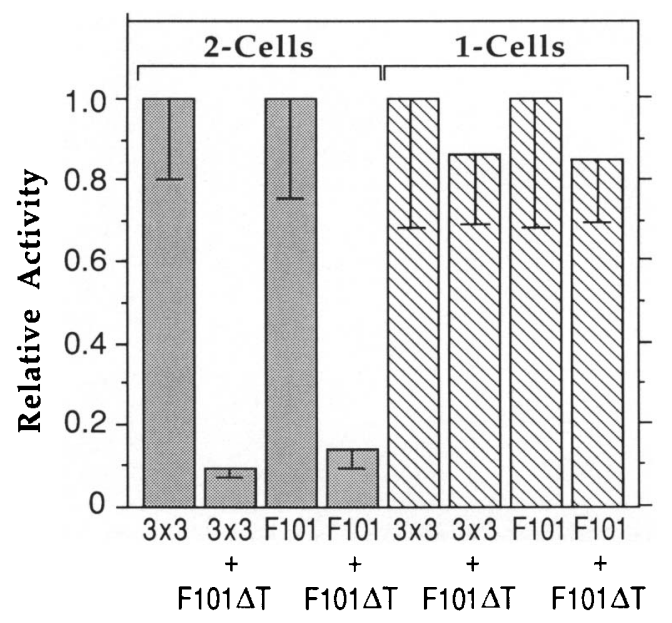

Figure 7. Competition for enhancer-binding factors in mouse embryos. p3 $\times 3$ tkluc $(3 \times 3)$ or pF101tkluc (F101) was injected into the male pronucleus of one-cell embryos or one of the zygotic nuclei of two-cell embryos $(0.4 \mathrm{pg}$ of DNA per nucleus). To detect competition for transcription factors, $0.2 \mathrm{pg}$ of pF101 $\Delta \mathrm{T}$ was coinjected; luciferase activity was measured 42 hr later as described in Fig. 2.

plasmid DNA into chromatin is inversely correlated with the level of gene expression, but it is not correlated with the need for enhancers (Table 2).

Chromatin assembly also was not correlated with DNA replication. Plasmids containing the PyV genome with the F101 enhancer (pF101) replicated with a similar efficiency in both naturally arrested one-cell embryos and in developing two-cell embryos, because the F101 enhancer strongly stimulates PyV T-ag synthesis from the PyV early gene promoter in two-cell embryos (Martínez-Salas et al. 1988). Because most replication occurred from 24 to $48 \mathrm{hr}$ postinjection, formation of chromatin in developing two-cell embryos appeared to be coupled to plasmid DNA replication. However, this was not the case in spontaneously arrested one-cell embryos. In fact, chromatin assembly in oocytes was clearly independent of DNA replication because oocytes neither replicated their own DNA nor that of injected plasmids (data not shown; Chalifour et al. 1986).

\section{Discussion}

Genes injected into mouse oocytes and embryos respond to the same controls that regulate endogenous gene expression

Mouse oocytes are transcriptionally and translationally active (Bachvarova 1985; Wassarman 1988), but transcription is greatly reduced upon meiotic maturation and does not resume until the fertilized egg cleaves into a two-cell embryo (Clegg and Piko 1982). Zygotic gene expression is detected first at $2-4 \mathrm{hr}$ after cleavage, but the maor onset of zygotic gene expression begins about 8-10 hr later (Bolton et al. 1984). Consistent with this pattern of endogenous gene expression, the tk promoter (data not shown), as well as the SV40 early and late gene promoters (Chalifour et al. 1986), rapidly initiated gene expression when injected into mouse oocytes, and the tk promoter responded rapidly when injected into two-cell embryos. However, expression was delayed 16-20 hr when injected into once-cell embryos (Fig. 8) arrested in aphidicolin, coincident with the onset of zygotic gene expression (Fig. 8; Chen et al. 1986). Inhibitors of DNA replication such as aphidicolin do not prevent the onset of zygotic gene expression, although they do block cell cleavage (Bolton et al. 1984; Poueymirou and Schultz 1987). The presence of a time-dependent mechanism for initiation of zygotic gene expression was confirmed by the fact that genes injected into one-cell embryos preincubated for $20 \mathrm{hr}$ in aphidicolin were expressed immediately (Fig. 8). This mechanism can reprogram nuclei from eight-cell embryos to synthesize proteins characteristic of early two-cell embryos when they are injected into one-cell embryos (Howlett et al. 1987). Thus, we conclude that expression of genes injected into mouse oocytes and embryos are subject to the same controls that regulate endogenous gene expression. In contrast, zygotic gene expression in Xenopus does not begin until at least five rounds of DNA replication have occurred (Newport and Kirshner 1982), suggesting that the mechanism by which zygotic genes are activated in mammals is fundamentally different from the mechanism used by amphibians.

The need for enhancers during mouse development first appears with formation of the zygotic nucleus

Studies on the transient expression of genes in mouse oocytes and embryos have begun to identify the cisacting sequences that regulate gene expression during early mouse development (Stuart et al. 1984; Wirak et al. 1985; Chalifour et al. 1987; Martínez-Salas et al. 1988; Strickland et al. 1988). Gene expression was promoter dependent, and the level of promoter activity depended on the amount of DNA injected (Fig. 2), the incubation time allowed after injection (Fig. 8), the stage of development (Figs. 3 and 6), and, in the case of developing twocell embryos, the presence of an appropriate enhancer (Fig. 4). Under optimal conditions, the tk promoter stimulated luciferase expression 12 -fold in oocytes, 566-fold in one-cell embryos, and 92-fold in developing two-cell embryos (Table 1 and Fig. 2). A single one-cell embryo produced an average of $28 \mathrm{pg}$ of luciferase with the most active cells producing up to $380 \mathrm{pg}$ of luciferase. This amounted to $0.1-1.5 \%$ of its total protein content (Brinster 1967). Although the levels of gene expression were 67-fold lower in oocytes than in embryos, the amount of expression per oocyte was greater than the highest levels observed in differentiated cells (Table 2; Chalifour et al. 1987). Although it is generally accepted that mRNA levels reflect protein levels, we cannot exclude the possibility that changes may occur in luciferase translation and stability as well as in luciferase synthesis from one developmental stage to the next. However, this does not affect comparisons of gene expression from different plasmids in the same cell. 


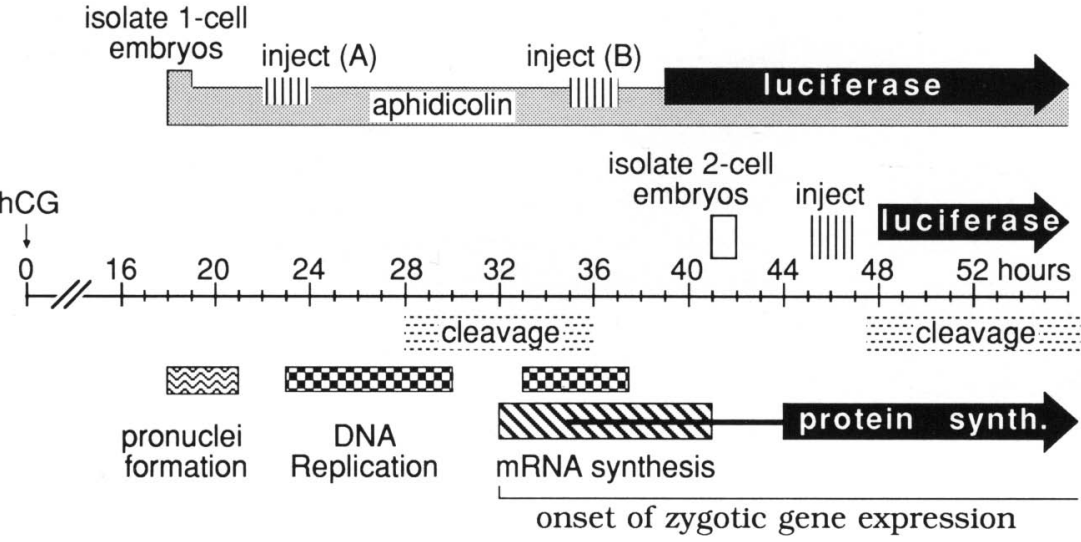

Figure 8. (A) Sequence of events during the first hours of mouse development are represented below the time line relative to the injection of human chorionic gonadotropin (hCG) hormone (data were take from Bolton et al. 1984 and Hogan et al. 1986). Protocols and results from microinjection experiments are represented above the time line. $(B)$ Luciferase activity in embryos injected with ptkluc presented as a function of time postinjection. The amount of activity in each panel was expressed as a fraction of the maximum amount observed in that experiment. One-cell embryos were injected either $4 \mathrm{hr}$ (sample A) or $16 \mathrm{hr}$ (sample B) after isolation and culture in aphidicolin. Two-cell embryos were isolated and cultured in the absence of aphidicolin. Shaded area in top panel highlights the time elapsed before the maximum expression of luciferase was observed. This shaded area is reproduced in 1-Cells (B) and 2-Cells to facilitate comparison. Error bars indicate the SEM. Results with pF10ltkluc were indistinguishable from ptkluc and therefore were not plotted.

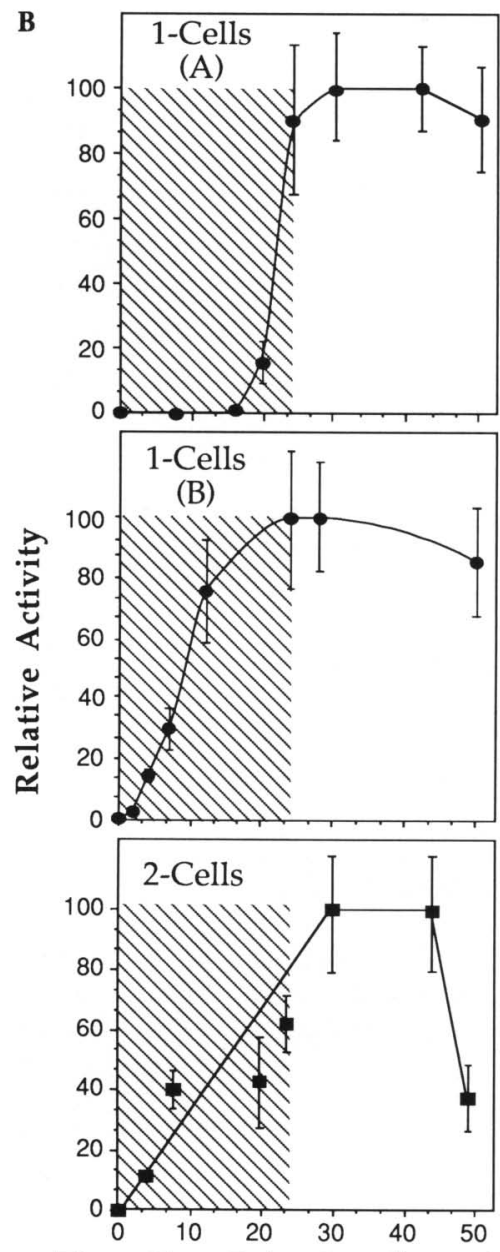

Time Post-Injection (hours)

Both RNA polymerase II and III promoters are recognized in mouse oocytes (Brinster et al. 1981). However, enhancers that can stimulate the SV40 early promoter and the HSV tk promoter by 100 -fold in a variety of mammalian cells (Table 2; Edlund et al. 1985; Mueller et al. 1988/ did not affect the activity of these promoters in oocytes (Fig. 4; Chalifour et al. 1987). This was not due to limited availability of transcription factors because these enhancers had no effect even when DNA concentrations were injected that expressed only $10-50 \%$ of the maximum level of luciferase activity observed. Although this may be due to the absence of appropriate enhancer activation proteins, it may also reflect the absence of negative regulatory factors that normally limit promoter activity. For example, SV40 early and late promoters are equally active in mouse oocytes, even though they normally require entirely different stimuli for activation in differentiated cells (Chalifour et al. 1986).

The same conclusions were reached when plasmids were injected into one-cell embryos, regardless of which pronucleus was injected (Fig. 4, Table 2). Furthermore, coinjection of plasmids containing enhancer elements did not repress luciferase expression in one-cell embryos as it did in developing two-cell embryos (Fig. 7), demon- strating that the remarkably high levels of gene expression observed in one-cell embryos were not dependent on enhancer binding proteins. This conclusion is confirmed by the fact that one-cell embryos are the only cells that allow the PyV origin of replication to function in the absence of its enhancer component (MartínezSalas et al. 1988). The PyV origin of replication is ninefold more active in one-cell embryos than in developing two-cell embryos, regardless of the presence or absence of an enhancer, and coinjection of the PyV enhancer region fails to inhibit replication in one-cell embryos under conditions that inhibit replication in developing two-cell embryos (Table 2).

The metal ion responsive elements (MRE) within the metallothionein promoter may represent an exception to our observations with viral enhancers. MRE also can replace enhancers in differentiated cells (Serfling et al. $1985 \mathrm{~b}$ ), and are active as promoter elements in mouse one-cell embryos (Brinster et al. 1982). However, although MRE can restore the activity of a crippled tk promoter in one-cell embryos (Stuart et al. 1984), they have not been shown to enhance the activity of a wild-type promoter or to stimulate gene expression at greater distances from the transcriptional start site.

Developing two-cell embryos were the earliest stage 


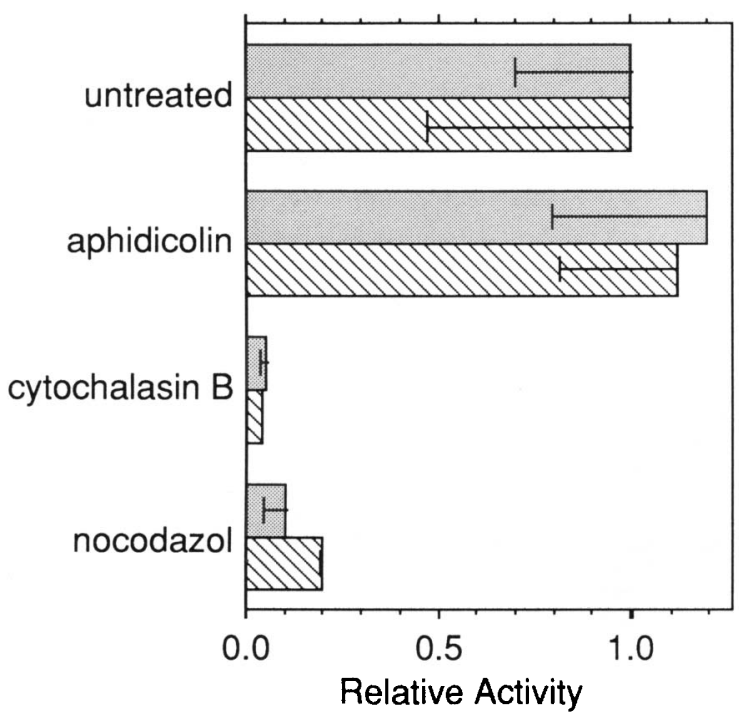

Figure 9. Relationship between gene expression and the cell division cycle. ptkluc $\{0.4 \mathrm{pg}$, shaded bars) or pF101tkluc $\{0.4$ $\mathrm{pg}$, striped bars| was injected into the male pronucleus of onecell embryos isolated and cultured in the absence of drugs. After injection, one group was cultured in medium containing 2 $\mu \mathrm{g} / \mathrm{ml}$ aphidicolin, another group in $10 \mu / \mathrm{ml}$ cytochalasin B, and another group in $1 \mu \mathrm{g} / \mathrm{ml}$ nocodazol. Luciferase activity was determined $42 \mathrm{hr}$ postinjection, and presented relative to the cells that remained as one-cell embryos in the untreated group.

in mouse development that enhancer elements were needed to stimulate gene expression or activate the PyV origin of DNA replication. The level of enhancer stimulation varied with the amount of DNA injected (Fig. 2). Enhancers stimulated the tk promoter 6 -fold when the amount of plasmid DNA injected was optimal for tk promoter activity (Table 1), and up to 21 -fold when suboptimal amounts of DNA were injected (Table 2). The 21fold stimulation resulted from a 2 -fold increase in the number of embryos that responded to the promoter and a 10 -fold increase in the average level of activity per embryo (Fig. 5). This was consistent with the response of differentiated cells to enhancers. Individual differentiated cells can form fully active transcription complexes without an enhancer present on the gene, but the presence of an enhancer increases the number of cells that form these complexes (Weintraub 1988). In contrast, the fraction of oocytes or one-cell embryos that responded to the injected gene was always about $90 \%$, regardless of the presence or absence of an enhancer.

\section{Gene expression is more sensitive than DNA replication to enhancer structure}

The PyV F101 enhancer was particularly effective in stimulating gene expression in early cleavage embryos (Fig. 6), although it exhibited no advantage over the PyV wild-type enhancer in activating the PyV ori-core (Table 2). F101 was selected originally for its increased activity in mouse embryonal carcinoma F9 cells (Fujimura et al. 1981), which share characteristics of primitive endoderm arising from the inner cell mass late in blastocyst development. However, the F101 enhancer was eight- to ninefold better at stimulating the tk promoter in two- to eight-cell embryos than in F9 cells (Fig. 6). F101 had a similar effect on the PyV early promoter in developing two-cell embryos (Martínez-Salas et al. 1988). Thus, enhancer mutations selected in mouse embryonic cell lines can respond to regulatory factors in mouse embryos. Furthermore, the fact that the both the 54-bp duplication and the point mutation at nucleotide 5233 were needed for activity in embryos indicates that an embryo-specific enhancer activation protein may bind to the junction formed by the tandem repeat.

Enhancer region 3 is a functional part of $\mathrm{PyV}$ ori in mouse embryos (Wirak et al. 1985; Martínez-Salas et al. 1988) but not in mouse EC cells (Fujimura and Linney 1982). The F101 enhancer mutation generates both a functional PyV ori in EC cells and stimulates the PyV early promoter (Fujimura and Linney 1982). Thus, proteins that recognize enhancer region 3 appear to be present soon after formation of two-cell embryos. These proteins are absent during the late blastocyst stage and then reappear in differentiated tissues, but the protein that recognizes F101 appears to exist from the two-cell embryo stage through the late blastocyst stage. In this way, the early embryo stages can allow origins of replication that may require enhancers to function at every cell division, while still regulating the expression of various genes as cells differentiate.

The fact that F101 improves enhancer region 3 for transcription but not for origin activation in mouse embryos (Table 2) confirms previous reports that $\mathrm{PyV}$ ori

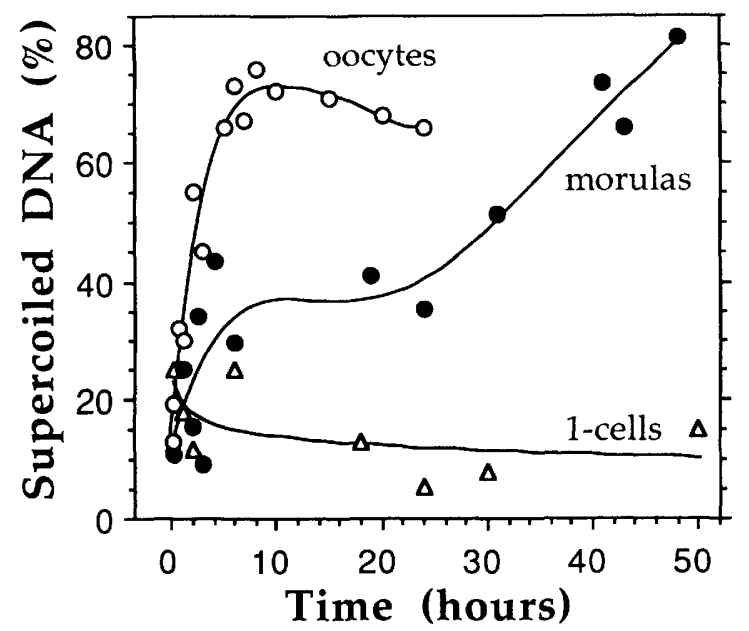

Figure 10. Chromatin assembly on DNA injected into the nucleus of mouse embryos as measured by formation of superhelical DNA. One-cell and two-cell embryos were injected with pF101 (Martínez-Salas et al. 1988). Groups of 10 embryos were collected at the indicated times after injection. The percentage of supercoiled plasmid present in the total DNA was calculated and plotted as a function of time postinjection. The data for oocytes were taken from Chalifour et al. (1986). 
Table 2. Requirements for PyV origin activity and tk-promoter activity under conditions optimal for enhancer activation in developing two-cell mouse embryos

\begin{tabular}{|c|c|c|c|c|c|}
\hline & \multicolumn{5}{|c|}{ PyV origin activity (relative) ${ }^{\mathbf{a}}$} \\
\hline & \multirow[b]{2}{*}{ oocytes } & \multicolumn{2}{|c|}{$\begin{array}{l}\text { One-cell } \\
\text { embryos }\end{array}$} & \multirow{2}{*}{$\begin{array}{l}\text { developing two-cell } \\
\text { embryos }\end{array}$} & \multirow{2}{*}{$\begin{array}{l}3 \mathrm{~T} 3 \\
\text { cells }\end{array}$} \\
\hline & & male & female & & \\
\hline ori-core & 0 & 9 & - & 0 & 0 \\
\hline ori-core/wt enhancer $(\alpha \beta)$ & 0 & 9 & - & 1 & 1 \\
\hline ori-core/F101 enhancer $\left(\alpha \beta^{\star}\right)$ & 0 & 9 & - & 1 & 1 \\
\hline \multirow[t]{2}{*}{ Enhancer competition } & & no & & yes & yes \\
\hline & \multicolumn{5}{|c|}{ HSV tk-promoter activity (relative) ${ }^{\mathbf{b}}$} \\
\hline Promoter & 0.6 & 38 & 18 & 1 & 1 \\
\hline Promoter/wt enhancer & 0.4 & 32 & 17 & 3 & 95 \\
\hline Promoter/F101 enhancer & 0.3 & 40 & 20 & 21 & 38 \\
\hline \multirow[t]{2}{*}{ Enhancer competition } & & no & & yes & yes \\
\hline & \multicolumn{5}{|c|}{ Chromatin assemblyc $(\%)$} \\
\hline ori-core/F101 enhancer & 70 & 15 & & 70 & 80 \\
\hline
\end{tabular}

aData are from Martínez-Salas et al. (1988). PyV ori-core and T-ag are always required for replication.

bata are from Figs. 4 and 7, and transfection of 3T3 cells. The tk-promoter was always required for luciferase expression. Luciferase activities in oocytes and embryos are expressed relative to the activity of ptkluc in developing two-cell embryos $\mid 394 \pm 90 ; 0.4 \mathrm{pg}$ of DNA/nucleus was defined as 1). Relative activities in 3T3 cells were calculated separately.

'Data are from Fig. 10 (42 hr postinjection). The same analysis was performed with 3T3 cells.

activity is relatively constant regardless of the number and effectiveness of the enhancer elements, while promoter activity is very sensitive to these parameters (Veldman et al. 1985; Campbell and Villarreal 1988; Martínez-Salas et al. 1988). Thus, the roles of enhancers in these two processes are not identical even though they may use the same enhancer-specific proteins (see introductory section/ and depend on the same components of nuclear structure.

The need for enhancers to activate promoters or origins of replication depends on some component of nuclear structure

Differences in the requirement for enhancers during mouse preimplantation development cannot be explained simply by the levels of soluble initiation factors. First, the levels of tk-promoter activity in oocytes was at least 63-fold lower than in one-cell embryos, but neither cell responded to enhancers. Second, the factors required to initiate replication at a papovavirus origin core (DePamphilis 1988) are distinctly different from those needed to activate the tk promoter (McKnight and Kingsbury 1982). Third, PyV origin core can function without an enhancer in a cell extract (Prives et al. 1987) as well as in one-cell embryos, even though the concentration of replication factors should be reduced substantially in the extract. Finally, the sequence requirements for promoter activity corresponded only to the type of nucleus in which the plasmid was placed (Fig. 4). Because the onset of zygotic gene expression is independent of DNA replication and happens to be at a precise time after fertilization, any initiation factors that substitute for enhancer function must decay at a constant rate.
Therefore, if the need for enhancers depended on the level of transcription factors, the role of enhancers would appear at a fixed time after fertilization, regardless of whether the injected gene was in a pronucleus or a zygotic nucleus.

Chromatin organization and assembly also cannot account for the sudden appearance of enhancer requirements after formation of two-cell embryos. Developing embryos are similar to oocytes in their synthesis of histones and assembly of plasmid DNA into chromatin (Table 2; Fig. 10). Concentrations of histones H2A, H2B, and $\mathrm{H} 3$ mRNAs decrease 5- to 10-fold as oocytes progress to one-cell embryos, and are then expressed at increasing levels following the onset of zygotic gene expression in diploid two-cell embryos /Graves et al.. 1985). No differences in the newly synthesized proteins of male and female pronuclei have been detected (Howlett et al. 1988). Neither oocyte germinal vesicles nor one-cell embryo pronuclei needed enhancers to fully express the injected gene, even though their chromatin structure differs greatly. Germinal vesicles contain condensed chromosomes in meiotic prophase and pronuclei contain open chromatin in late $G_{1}$ or early $S$ phase. Oocytes were also the most efficient at assembling plasmid DNA into chromatin but one-cell embryos were least efficient. Only the level of gene expression was correlated with chromatin structure and assembly (Table 2); oocytes were least efficient at gene expression but onecell embryos were most efficient. This is consistent with other studies showing that transcriptional activity is inversely related to chromatin assembly. Nucleosome assembly can prevent binding of transcription factors to promoters (Workman and Roeder 1987), which could explain why ribosomal genes organized into nucleosomes 
are transcriptionally inactive, while those lacking a repeated nucleosome structure are active (Conconi et al. 1989).

The fact that enhancers were not needed to express injected genes fully or to activate the PyV origin core until formation of the first zygotic nucleus suggests that the need for enhancers depends on some negative regulatory factor that first appears as a component of zygotic nuclear structure. This structure must be fundamental to enhancer action because it is common to both promoters and origins of replication. In the absence of nuclear and chromatin structures, the PyV origin-core functions without an enhancer (Prives et al. 1987). Enhancers can stimulate promoters in soluble in vitro systems, but they have a much smaller stimulatory effect in vitro than in vivo (Treisman and Maniatis 1985). However, zygotic nuclei, in developing two-cell embryos, respond to enhancers by raising the level of tkpromoter activity from one that is similar to that observed in oocytes to one that is equivalent to one-cell embryos (Table 2; 2-8 cell embryos in Fig. 6). Perhaps enhancer elements, when associated with enhancer-specific-binding factors, release the promoter or origin of replication from its attachment to a nuclear binding site. In this way, the basal level of activity for genes destined to be expressed in specific target cells can be turned off in order to prevent their expression at inappropriate times during development.

\section{Methods \\ Construction of plasmids}

ptkluc is a derivative of pTE1 (Edlund et al. 1985) in which the luciferase gene, encoded in a 2572-bp HindIII-BamHI fragment from pSV232AL-AD5' along with SV40 splicing and polyadenylation signals (deWet et al. 1987), was substituted for the HindIII-BamHI fragment (1634 bp) from pSV2cat encoded the CAT gene (Fig. 1). The HSV tk promoter, nucleotides -109 to +50 , with a BamHI upstream linker (McKnight and Kingsbury 1982) was flanked by SacI linkers at each end. The 600 -bp spacer corresponded to the pBR322 BamHI-NruI fragment (nucleotides 375-972). HindIII and BgIII are unique sites for insertion of enhancer regions in the polylinker. The cloning vector consists of the NruI-EcoRI fragment of pBR322 (nucleotides 972-4361), flanked by BamHI linkers, destroying the NruI site. Elimination of the 180-bp SacI-SacI fragment yielded the promoterless plasmid pluc.

Plasmid pl23tkluc contains PyV A2 enhancer region $1+2+3$ in the orientation indicated, 600 bp upstream of the tk promoter (Fig. 1). Other plasmids are similarly designated. For example, pl3tkluc contains nucleotides 5039-5092 plus nucleotides $5130-5264$ cloned 600 bp upstream of the tk promotor. p23tkluc contains nucleotides 5073-5264, and p3 $\times 3$ tkluc contain 3 copies of nucleotides $5130-5264$. These plasmids were constructed by isolating the HindIII insert in pTEl derivatives that contained PyV enhancer elements (Mueller et al. 1988) and ligating them to HindIII-linearized ptkluc. pF441tkluc, pF11ltkluc, and pFl01tkluc contain the 137-, 168-, and 191-bp PvuII fragments from pyF441, pyF111, and pyF101, respectively (Fujimura et al. 1981). HindIII linkers were added to these fragments and then ligated to HindIII-linearized ptkluc. pF101 $\Delta \mathrm{T}$ encodes a truncated $\mathrm{T}$ antigen driven by the PyV early promoter (Martínez-Salas et al. 1988).
Plasmids were grown in Escherichia coli DH5 and purified through two cesium chloride gradients before injection (Martínez-Salas et al. 1988).

\section{Transfection of DNA into differentiated mouse cells}

Mouse 3T3 fibroblasts grown on $60-\mathrm{mm}$ dishes to $50 \%$ confluency were transfected with $3 \mu \mathrm{g}$ of plasmid DNA supplemented with $10 \mu \mathrm{g}$ of carrier DNA, by calcium phosphate (Wigler et al. 1978) or by DEAE-dextran (de la Torre et al. 1987), except that $500 \mu \mathrm{g} / \mathrm{ml}$ of DEAE-dextran were used. Extracts were prepared from $1 \times 10^{6}$ to $2 \times 10^{6}$ cells 24 and $42 \mathrm{hr}$ later (deWet et al. 1987) and luciferase activity measured. Relative stimulation of tk-promoter activity by PyV A2 enhancer elements and by PyV F9 enhancer mutations (Table 2 and data not shown) were in agreement with analogous assays performed by Mueller et al. (1988) and Linney and Donerly (1983), respectively. Relative activity of PyV A2 enhancer elements was reduced in MOP8 cells compared to $3 \mathrm{~T} 3$ cells as a result of increased activity of ptkluc (e.g., fivefold for p123tkluc).

\section{Injection of DNA into mouse oocytes and embryos}

Isolation, culture, and microinjection of mouse oocytes and embryos were carried out as described in DePamphilis et al. (1988a). Oocytes were obtained from 17- to 19-day-old CDl mice and cultured in minimal essential medium (Sigma) in the presence of $100 \mu \mathrm{g} / \mathrm{ml} \mathrm{dbcAMP}$ so that about $85 \%$ retained their germinal vesicle. One-cell embryos were isolated $17-18 \mathrm{hr}$ after hCG was injected into 7- to 8-week-old CD1 females. Embryos were cultured in Whitten and Bigger's media supplemented with $40 \mu \mathrm{M}$ EDTA and $2 \mu \mathrm{g} / \mathrm{ml}$ of aphidicolin (Sigma), except where indicated. Two-cell embryos were isolated $40-42$ hr after hCG injection and were cultured in Whitten and Bigger's medium plus EDTA, unless indicated.

Groups of $100-150$ embryos at a time were injected with $2 \mathrm{pl}$ of superhelical plasmid DNA into one of their nuclei using the same needle and an automated injection system (Eppendorf microinjector 5242). The amount of DNA injected was determined as described previously (Martínez-Salas et al. 1988). Survivors were cultured for the time indicated before harvesting individual embryos and measuring luciferase activity.

\section{Luciferase assay}

Individual embryos were harvested in $50 \mu$ l of reaction buffer [25 mM glycylglycine (pH 7.8), $15 \mathrm{~mm} \mathrm{MgSO}_{4}, 5 \mathrm{mM}$ ATP (pH 7), $100 \mu \mathrm{g} / \mathrm{ml}$ bovine serum albumin, $1 \mathrm{~mm}$ dithiothreitol], subjected to three cycles of freeze-thawing $\left(-70^{\circ} \mathrm{C}\right.$ to $\left.37^{\circ} \mathrm{C}\right)$ and then assayed in the presence of $1 \mathrm{~mm}$ luciferin (Analytical Luminiscence). Light emission from extracts of microinjected embryos or transfected cells were integrated for the initial $10 \mathrm{sec}$ of emission at $25^{\circ} \mathrm{C}$ in a luminometer (Monolight 2001, Analytical Luminiscence). Each group of assays was standardized using aliquots of purified luciferase (Sigma) stored at $-70^{\circ} \mathrm{C}$, and light unit data were corrected for small variations from one experiment to the next. Luciferase activity was expressed as scintillations per $10 \mathrm{sec}$ ( $1 \mathrm{pg}$ of purified luciferase gave 1799 scintillations per $10 \mathrm{sec}$. This assay was linear from $10 \mathrm{fg}$ to $1 \mu \mathrm{g}$ of luciferase.

An average of 55 embryos was used per experiment. On each experiment, the mean \pm the standard error of the mean (SEM) is given and has been used to compare with other equivalent experiments. The SEM among individual oocytes or one-cell embryos for a single experiment was $10-26 \%$ of the mean. The SEM for ptkluc in two-cell embryos was as large as $38 \%$ of the 
mean. However, linking the tk promoter to an enhancer resulted in two-cell embryo data equivalent to those from onecell embryos. The mean values derived from independent experiments were quite reproducible; the SEM for three independent experiments $(30-70$ embryos per experiment $)$ was $10-20 \%$ of the mean.

Detection of superhelicity of DNA injected into mouse embryos and transfected 3T3 cells

Total DNA from injected embryos was isolated, fractionated by electrophoresis on agarose gels, and then visualized by autoradiography after blotting-hybridization to pF101-labeled DNA (Martínez-Salas et al. 1988). Nucleoprotein complexes from 3T3 cells transfected with pF101 by the DEAE-dextran method, were prepared $42 \mathrm{hr}$ later as described in Su and DePamphilis (1978). Results with one-cell embryos were independent of the method of DNA preparation (SDS lysis or alkaline lysis), the injection buffer (phosphate buffer or Tris-EDTA), the mouse strain (CD-1 or B57SJL), and the ability of the plasmid to replicate (pF101 or $\mathrm{pML} 1)$.

\section{Acknowledgments}

We thank Steve Herman and Ron Goldkorn for preparing pluc and ptkluc and helping with luciferase assays, Miriam Miranda for helping with the isolation and culturing of embryos, and Crisanto Gutierrez for statistical analysis of the data and for his good humor during hard times. E.M.S. was partially supported by a Fogarty International Fellowship from National Institutes of Health, number 1-F05-TW04021-01.

\section{References}

Amati, P. 1985. Polyoma regulating region: A potential probe for mouse cell differentiation. Cell 43: 561-562.

Bachvarova, R. 1985. Gene expression during oogenesis and oocyte development in mammals. In Developmental biology, oogenesis (ed. L.W. Browder), vol. 1. Plenum Press, New York, New York.

Bohnlein, E. and P. Gruss. 1986. Interaction of distinct nuclear proteins with sequences controlling the expression of polyomavirus early genes. Mol. Cell. Biol. 6: 1401-1411.

Bolton, V.N., P.J. Oades, and M.H. Johnson. 1984. The relationship between cleavage, DNA replication, and gene expression in the mouse 2-cell embryo. J. Embryol. Exp. Morphol. 79: $139-163$.

Brinster, R.L. 1967. Protein content of the mouse embryo during the first five days of development. J. Reprod. Fertil. 13: 413-420.

Brinster, R.L., H.Y. Chen, and M.E. Trumbauer. 1981. Mouse oocytes transcribe injected Xenopus 5S RNA gene. Science 211: 396-398.

Brinster, R.L., H.Y. Chen, R. Warren, A. Sarthy, and R.D. Palmiter. 1982. Regulation of metallothionein-thymidine kinase fusion plasmids injected into mouse eggs. Nature 296: 39-42.

Campbell, B.A. and L.P. Villarreal. 1986. Lymphoid and other tissue specific phenotypes of polyoma virus enhancer recombinants: Positive and negative combinational effects on enhancer specificity and activity. Mol. Cell. Biol. 6: 20682079.

- . 1988. Functional analysis of the individual enhancer core sequences of Polyomavirus: Cell-specific uncoupling of DNA replication from transcription. Mol. Cell. Biol. 8: 1993-2004.
Chalifour, L.E., D.O. Wirak, P.M. Wassarman, and M.L. DePamphilis. 1986. Expression of simian virus 40 early and late genes in mouse oocytes and embryos. J. Virol. 59: 619.

Chalifour, L.E., D.O. Wirak, U. Hansen, P.M. Wassarman, and M.L. DePamphilis. 1987. cis- and trans-acting sequences required for expression of simian virus 40 genes in mouse oocytes. Genes Dev. 1: 1096-1106.

Chandrasekharappa, S.C. and K.N. Subramanian. 1987. Effects of positions and orientation of the 72-base-pair-repeat transcriptional enhancer on replication from the simian virus 40 core origin. J. Virol. 61: 2973-2980.

Chen, H.I., M.E. Trumbauer, K.M. Ebert, R.D. Palmiter, and R.L. Brinster. 1987. Developmental changes in the response of mouse eggs to injected genes. In Molecular developmental biology, pp. 149-159. Alan R. Liss, New York.

Clegg, K.B. and L. Piko. 1982. RNA synthesis and cytoplasmic polyadenylation in the one-cell mouse embryo. Nature 295: 342-345.

Conconi, A., R.M. Widmer, T. Koller, and J.M. Sogo. 1989. Two different chromatin structures coexist in ribosomal RNA genes throughout the cell cycle. Cell 57: 753-761.

de la Torre, J.C., B. Alarcon, E. Martínez-Salas, L. Carrasco, and E. Domingo. 1987. Ribavirin cures cells of a persistent infection with foot-and-mouth disease virus in vitro. $J$. Virol. 61: 233-235.

DePamphilis, M.L. and M.K. Bradley. 1986. Replication of SV40 and polyoma virus chromosomes. In The papovaviridae led. N.P. Salzman), vol. 1. pp. 99-246. Plenum Press, New York.

DePamphilis, M.L. 1988. Transcriptional elements as components of origins of eukaryotic DNA replication. Cell 52: 635-638.

DePamphilis, M.L., S.A. Herman, E. Martínez-Salas, L.E. Chalifour, D.O. Wirak, D.Y. Cupo, and M. Miranda. 1988a. Microinjecting DNA into mouse ova to study DNA replication and gene expression and to produce transgenic animals. BiOTechniques 6: 662-680.

DePamphilis, M.L., E. Martínez-Salas, D.Y. Cupo, E.A. Hendrickson, C.E. Fritze, W.R. Folk, and U. Heine. 1988b. Initiation of polyomavirus and SV40 DNA replication, and the requirements for DNA replication during mammalian development. In Eukaryotic DNA replication /ed. B. Stillman and T. Kelly), Cancer Cells, vol. 6, pp. 165-175. Cold Spring Harbor Laboratory, Cold Spring Harbor, New York.

deVillers, J., W. Schaffner, C. Tyndall, S. Lupton, and R. Kamen. 1984. Polyoma virus DNA replication requires an enhancer. Nature 312: 242-246.

deWet, J.R., K.V. Wood, M. DeLuca, D.R. Helinski, and S. Subramani. 1987. Firefly luciferase gene: Structure and expression in mammalian cells. Mol. Cell. Biol. 7: 725-737.

Edlund, T., M.D. Walker, P.J. Barr, and W.J. Rutter. 1985. Cellspecific expression of the rat insulin gene: Evidence for role of two distinct 5' flanking elements. Science 230: 912-916.

Fujimura, F.K. 1986. Nuclear activity from F9 embryonal carcinoma cells binding specifically to the enhancers of wildtype polyoma virus and PyEC mutant DNAs. Nucleic Acids Res. 14: 2845-2861.

Fujimura, F.K., P.L. Deininger, T. Friedmann, and E. Linney. 1981. Mutation near the polyoma DNA replication origin permits productive infection of F9 embryonal carcinoma cells. Cell 23: 809-814.

Fujimura, F.K. and E. Linney. 1982. Polyoma mutants that productively infect F9 embryonal carcinoma cells do not rescue wild-type polyoma in F9 cells. Proc. Natl. Acad. Sci. 79: 1479-1483.

Gargiulo, G., F. Razvi, and A. Worcel. 1984. Assembly of tran- 
scriptionally active chromatin in Xenopus oocytes requires specific DNA binding factors. Cell 38: 511-521.

Graves, R.A., W.F. Marzluff, D.H. Giebelhaus, and G.A. Schultz. 1985. Quantitative and qualitative changes in histone gene expression during early mouse embryo development. Proc. Natl. Acad. Sci. 82: 5685-5689.

Hassell, J.A., W.J. Muller, and C.R. Mueller. 1986. The dual role of the polyomavirus enhancer in transcription and DNA replication. In DNA tumor viruses, Cancer Cells, vol. 4, pp. 561-569. Cold Spring Harbor Laboratory, Cold Spring Harbor, New York.

Hendrickson, E.A., C.F. Fritze, W.R. Folk, and M.L. DePamphilis. 1987. The origin of bidirectional DNA replication in polyoma virus. EMBO J. 6: $2011-2018$.

Hogan, B., F. Costantini, and E. Lacy. 1986. Manipulating the mouse embryo: A laboratory manual. Cold Spring Harbor Laboratory, Cold Spring Harbor, New York.

Howlett, S.K., S.C. Barton, and M.A. Surani. 1987. Nuclear cytoplasmic interactions following nuclear transplantation in mouse embryos. Development 101: 915-923.

Howlett, S.K., S.C. Barton, and A.H. Surani. 1988. Nuclear and cytoplasmic localization of newly synthesized proteins in the early mouse embryo. Development 103: 129-134.

Kovesdi, I., M. Satake, K. Furukawa, R. Reichel, Y. Ito, and R. Nevins. 1987. A factor discriminating between the wildtype and a mutant polyoma virus enhancer. Nature 328: 87-89.

Linney, E. and S. Donerly. 1983. DNA fragments from F9 PyEC mutants increase expression of heterologous genes in transfected F9 cells. Cell 35: 693-699.

Martin, M.E., J. Piette, M. Yaniv, W.-J. Tang, and W. Folk. 1988. Activation of the polyomavirus enhancer by a murine activator protein 1 (AP1) homolog and two contiguous proteins. Proc. Natl. Acad. Sci. 85: 5839-5843.

Martínez-Salas, E., D.Y. Cupo, and M.L. DePamphilis. 1988. The need for enhancers is acquired during mammalian development with formation of a diploid nucleus. Genes Dev. 2: 115-126.

McKnight, S.L., E.R. Gavis, and R. Kingsbury. 1981. Analysis of transcriptional regulatory signals of the HSV thymidine kinase gene: Identification of an upstream control region. Cell 25: 385-398.

McKnight, S.L. and R. Kingsbury. 1982. Transcriptional control signals of a eukaryotic protein-coding gene. Science 217: 316-324.

Mueller, C.R., W.J. Muller, and J.A. Hassell. 1988. The Polyomavirus enhancer comprises multiple functional elements. I. Virol. 62: 1667-1678.

Muller, W.J., C.R. Mueller, A.M. Mes, and J. Hassell. 1983. Polyomavirus origin for DNA replication comprises multiple genetic elements. I. Virol. 47: 586-599.

Newport, J. and M. Kirshner. 1982. A major developmental transition in early Xenopus embryos. II. Control of the onset of transcription. Cell 30: 687-696.

O'Connor, D.T. and S. Subramani. 1988. Do transcriptional enhancers also augment DNA replication? Nucleic Acids Res. 23: 11207-11222.

Ostapchuk, P., J.F.X. Diffley, J.T. Bruder, B. Stillman, A.J. Levine, and P. Hearing. 1986. Interaction of a nuclear factor with the polyoma virus enhancer region. Proc. Natl. Acad. Sci. 83: 8550-8554.

Piette, J. and M. Yaniv. 1986. Molecular analysis of the interaction between an enhancer binding factor and its DNA target. Nucleic Acids Res. 14: 9595-9611.

Poccia, D., T. Greenough, E. Nash, J. Erickson, and M. Gibbs. 1984. Remodeling of sperm chromatin following fertiliza- tion: Nucleosome repeat length and histone variant transitions in the absence of DNA synthesis. Dev. Biol. 104: 274286.

Poueymirou, W.T. and R.M. Schultz. 1987. Differential effects of activators of cAMP-dependent protein kinase and protein kinase $\mathrm{C}$ on cleavage of one-cell mouse embryos and protein synthesis and phosphorylation in one- and two-cell embryos. Dev. Biol. 121: 489-498.

Prives, C., Y. Murakami, F.J. Kern, W. Folk, C. Basilico, and J. Hurwitz. 1987. DNA sequence requirement for replication of polyoma virus DNA in vivo and in vitro. Mol. Cell. Biol. 7: 3694-3704

Rochford, R., B.A. Campbell, and L.P. Villarreal. 1987. A pancreas specificity results from the combination of polyoma virus and Moloney murine leukemia virus enhancer. Proc. Natl. Acad. Sci. 84: 449-453.

Satake, M., K. Furukawa, and Y. Ito. 1988. Biological activities of oligonucleotides spanning the F9 point mutation within the enhancer region of polyomavirus DNA. I. Virol. 62: 970-977.

Serfling, E., M. Jasin, and W. Schaffner. 1985a. Enhancers and eukaryotic gene transcription. Trends Genet. 1: 224-230.

Serfling, E., A. Lübbe, Dorsch-Häsler, and W. Schaffner. 1985b. Metal-dependent SV40 viruses containing inducible enhancers from the upstream region of metallothionein genes. EMBO I. 4: 3851-3859.

Strickland, S., J. Huarte, D. Belin, A. Vassalli, R.J. Rickles, and J.D. Vassalli. 1988. Antisense RNA directed against the 3'noncoding region prevents dormant RNA activation in mouse oocytes. Science 241: 680-684.

Stuart, G.W., P.F. Searle. H.Y. Chen, R.L. Brinster, and R.D. Palmiter. 1984. A 12 base pair DNA motif that is repeated several times in metallothionein gene promoters confers metal regulation to a heterologous gene. Proc. Natl. Acad. Sci. 81: 7318-7322.

Su, R.T. and M.L. DePamphilis. 1978. Simian virus 40 DNA replication in isolated replicating viral chromosomes. $I$. Virol. 28: 53-65.

Tang, W.J., S.L. Berger, S.J. Triezenberg, and W.R. Folk. 1987. Nucleotides in the polyoma virus enhancer that control viral transcription and DNA replication. Mol. Cell. Biol. 7: $1681-1690$.

Treisman, R. and T. Maniatis. 1985. Simian virus 40 enhancer increases number of RNA polymerase II molecules on linked DNA. Nature 315: 72-77.

Veldman, G.M., S. Lupton, and R. Kamen. 1985. Polyoma virus enhancer contains multiple redundant elements that activate both DNA replication and gene expression. Mol. Cell. Biol. 5: 649-658.

Wassarman, P.M. 1988. The mammalian ovum. In The physiology of reproduction (ed. E. Knobil, J. Neil, et al.), pp. 69-101. Raven Press, Ltd., New York.

Weintraub, H. 1988. Formation of stable transcription complexes as assayed by analysis of individual templates. Proc. Nat1. Acad. Sci. 85: 5819-5823.

Wigler, M., Pellicer, S. Silverstein, and R. Axel. 1978. Biochemical transfer of single-copy eukaryotic genes using total cellular DNA as donor. Cell 14: 725-731.

Wirak, D.O., L.E. Chalifour, P.M. Wassarman, W.J. Muller, J.A. Hassell, and M.L. DePamphilis. 1985. Sequence dependent DNA replication in preimplantation mouse embryos. Mol. Cell. Biol. 5: 2924-2935.

Workman, J.L. and R.G. Roeder. 1987. Binding of transcription factor TFID to the major late promoter during in vitro nucleosome assembly potentiates subsequent initiation by RNA polymerase II. Cell 51: 613-622. 


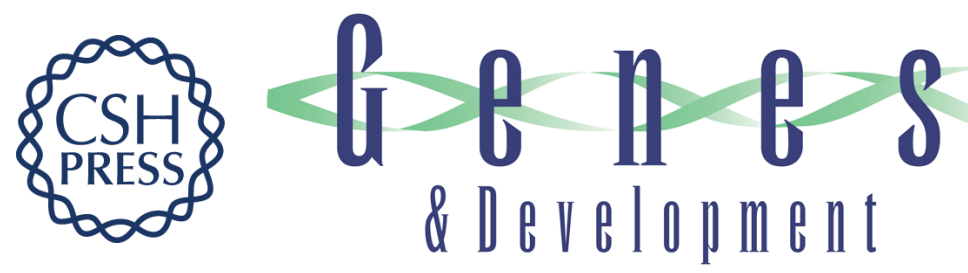

\section{The need for enhancers in gene expression first appears during mouse development with formation of the zygotic nucleus.}

E Martínez-Salas, E Linney, J Hassell, et al.

Genes Dev. 1989, 3:

Access the most recent version at doi:10.1101/gad.3.10.1493

References This article cites 56 articles, 30 of which can be accessed free at:

http://genesdev.cshlp.org/content/3/10/1493.full.html\#ref-list-1

License

Email Alerting

Service

Receive free email alerts when new articles cite this article - sign up in the box at the top right corner of the article or click here.

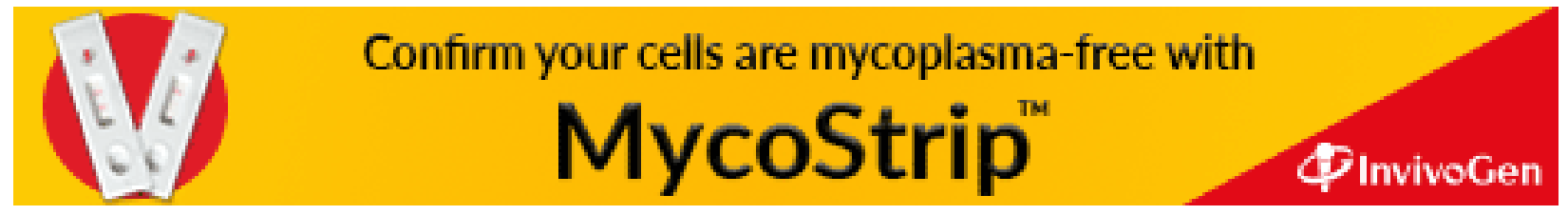

